\title{
Editorial
}

\section{Hospital-Based Influenza and Pneumococcal Vaccination: Sutton's Law Applied to Prevention}

\author{
David S. Fedson, MD; Peter Houck, MD; Dale Bratzler, DO, MPH
}

\begin{abstract}
Pneumonia and influenza continue to be two of the major causes of hospitalization and death throughout the world. It is fitting that this issue of the Journal is devoted to addressing these important topics. Many of these cases are caused by influenza virus and Streptococcus pneumoniae and could be prevented if the delivery of influenza and pneumococcal vaccines were more effectively targeted to those individuals who are otherwise destined to be hospitalized or to die due to one of these diseases. That persons with vaccine-preventable influenza and pneumococcal infections are still admitted to our hospitals is a sobering reminder that there still is important work to do.

Early in their education, virtually all medical students are taught the importance of following Sutton's Law in formulating a differential diagnosis. Sutton's Law is based on the remark made by the notorious bank robber, Willie Sutton. When asked why he robbed banks, he replied, "That's where the money is." In formulating a differential diagnosis, the student is advised to think first of common problems, not rare diseases. More often than not, diagnosing a common problem is "where the money is."
\end{abstract}

Sutton's Law also can be applied to the prevention of influenza and pneumococcal infections. In this instance, the question asked is, "What is the best vaccination strategy for reaching people who, if not vaccinated, will have the greatest likelihood of being hospitalized or dying of these two diseases?" The answer is patients who are being discharged from the hospital. Hospital-based influenza and pneumococcal vaccination is "where the money is."

In this commentary, we will address the following six issues: (1) the epidemiological rationale for hospital- based influenza and pneumococcal vaccination; (2) the translation of these epidemiological findings into clinical and public policy; (3) changes in the scientific understanding of the benefits of influenza and pneumococcal vaccination; (4) experience in implementing hospitalbased programs for vaccination; (5) practical issues for hospital-based vaccination; and (6) an enhanced role for infection control practitioners in ensuring that Sutton's Law for influenza and pneumococcal vaccination is followed.

\section{THE EPIDEMIOLOGICAL RATIONALE FOR HOSPITAL-BASED INELUENZA AND PNEUMOCOCCAL VACCINATION}

The first evidence that administering influenza vaccine to discharged patients might be worthwhile appeared in a short publication and an accompanying editorial published in $1983 .{ }^{1,2}$ Among 112 patients admitted to two teaching hospitals with pneumonia and influenza or chronic pulmonary diseases during the $\mathrm{A} / \mathrm{Texas} / 77$ influenza outbreak period, $38 \%$ had been previously discharged during the same year and $21 \%$ within the preceding 2 to 3 months. Only 2 of the 112 patients had been vaccinated.

A more substantial study was reported 9 years later (Table 1). ${ }^{3}$ In this population-based study, the adult population was divided into the following three mutually exclusive groups: (1) those who had been discharged from hospital during the 3-month fall vaccination season in 1982; (2) those who had not been discharged but had made at least one visit to a physician during the vaccination season; and (3) those who had had no contact with the healthcare system during the same period. The three groups were followed through the subsequent 1982/83 influenza outbreak period. Although discharged elderly

From Aventis Pasteur MSD (Dr. Fedson), Lyon, France; Health Care Financing Administration (Dr. Houck), Seattle, Washington; Oklahoma Foundation for Medical Quality (Dr. Bratzler), Oklahoma City, Oklahoma.

Address reprint requests to David S. Fedson, MD, Aventis Pasteur MSD, 8, rue Jonas Salk, 69367 Lyon Cedex 07, France.

The authors thank Astutie Michel for assistance in preparing the manuscript.

OO-ED-172. Fedson DS, Houck $P$, Bratzler D. Hospital-based influenza and pneumococcal vaccination: Sutton's Law applied to prevention. Infect Control Hosp Epidemiol 2000;21:692-699. 
TABLE 1

Epidemiological Rationale for HosptTal-Based Influenza Vaccination: Manitoba Influtenza Study, 1982 to 1983 .* Percentage of Persons with Hospital Discharge During the Influenza Vaccination Season ${ }^{\dagger}$ Who Were Included among All Persons Who Were Hospitalized or Died Durng the Influenza Outbreak Period ${ }^{\ddagger}$

\begin{tabular}{|c|c|c|c|c|c|c|c|}
\hline \multirow{3}{*}{$\begin{array}{l}\text { Age } \\
\text { Group (y) }\end{array}$} & \multirow{3}{*}{$\begin{array}{c}\text { Population } \\
\text { Total }\end{array}$} & \multirow{2}{*}{\multicolumn{2}{|c|}{$\begin{array}{l}\text { Hospltal Discharge } \\
\text { During the Influenza } \\
\text { Vacclnation Season }\end{array}$}} & \multicolumn{2}{|c|}{ Hospitalized } & \multicolumn{2}{|c|}{ Dled In Hosphtal } \\
\hline & & & & \multirow{2}{*}{$\begin{array}{c}\mathbf{P}+\mathbf{I}^{5} \\
\%\end{array}$} & \multirow{2}{*}{$\begin{array}{l}\text { All Respiratory } \\
\text { Conditions } \%\end{array}$} & \multirow{2}{*}{$\begin{array}{c}\mathbf{P}+\mathbf{I} \\
\%\end{array}$} & \multirow{2}{*}{$\begin{array}{l}\text { All Resplratory } \\
\text { Condltions \% }\end{array}$} \\
\hline & & No. & $\%$ & & & & \\
\hline $25-44$ & 297,540 & 8,046 & 3 & 11 & 19 & 65 & 74 \\
\hline $45-64$ & 198,120 & 6,439 & 3 & 32 & 31 & 82 & 63 \\
\hline $65-74$ & 74,664 & 4,811 & 6 & 39 & 44 & 62 & 67 \\
\hline$\geqslant 75$ & 44,138 & 5,188 & 12 & 45 & 46 & 66 & 66 \\
\hline \multicolumn{8}{|c|}{$\begin{array}{l}\text { Abbreviation: P+I, pneumonia and influenza. } \\
\text { * Adapted from Fedson DS, Wajda A, Nicol JP, Roos LL. }{ }^{3} \text { Calculations were based on a probability sample of } 100,000 \text { persons aged } \geqslant 25 \text { y. } \\
\text { † Influenza vaccination season, September 1-November } 30,1982 \text {. } \\
\text { † Influenza outbreak period, December 1, 1982-February } 28,1983 \text {. } \\
\text { \$ Discharged with P+I, ICD-9-CM } 480-487 \text {, all diagnostic positions. } \\
\text { |t Discharged with any respiratory condition, ICD-9-CM 466, } 480-487,490-496 \text {, and } 500-519 \text {, all diagnostic positions. }\end{array}$} \\
\hline
\end{tabular}

patients accounted for only $6 \%$ to $12 \%$ of all elderly persons, they accounted for $39 \%$ to $46 \%$ of all subsequent influenza-related hospital admissions and approximately two thirds of all influenza-related deaths. Among all persons 45 to 64 years in age, only $3 \%$ had been discharged during the vaccination season; yet, this group accounted for approximately one third of all influenza-related hospital admissions and more than two thirds of the deaths. Similar findings for influenza-related deaths were observed in young adults.

The epidemiological rationale for hospital-based pneumococcal vaccination also emerged in the early 1980 s from a population-based study conducted in Oxfordshire in the United Kingdom ${ }^{4}$ and a series of cases reported from a teaching and a community hospital in the United States. ${ }^{5}$ In the Oxfordshire study, $39 \%$ of pneumonia (all-cause) patients who survived hospitalization and $49 \%$ of those who died were found to have been discharged from hospital within the previous 5 years (a 5year period was chosen because it was believed then, as now, that a substantial degree of protection persists for at least 5 years following pneumococcal vaccination). In the US case study, $60 \%$ of 126 teaching hospital patients with pneumococcal bacteremia who survived and $70 \%$ of those who died had been discharged within the previous 5 years. ${ }^{5}$ Similar rates were found among 39 bacteremia patients in the community hospital.

Additional reports from the United States and the United Kingdom reinforced these findings. ${ }^{6,7}$ The US studies showed that $50 \%$ to $66 \%$ of bacteremic patients who survived and $67 \%$ to $78 \%$ of those who died had been discharged within the previous 3 to 5 years. ${ }^{6}$ Later, in 1990, a population-based study was reported from the Shenandoah region of Virginia. ${ }^{8}$ It was modeled after the earlier Oxfordshire study, and its findings were almost identical. Among elderly persons ( $\geqslant 65$ years) hospitalized with pneu- monia (all-causes; admission diagnosis, first-listed discharge diagnosis, or any discharge diagnosis), approximately $60 \%$ to $65 \%$ had been discharged within the previous 4 years. In both the Oxfordshire and Shenandoah studies, it was estimated that vaccinating 60 to 100 discharged patients would prevent within the next 5 years one hospital readmission with pneumococcal pneumonia. ${ }^{4,8}$

\section{THE TRANSLATION OF EPIDEMIOLOGICAL FINDINGS INTO CLINICAL AND PUBLIC POLICY FOR HOSPITAL-BASED INFLUENZA AND PNEUMOCOCCAL VACCINATION}

Epidemiological investigations, conducted for the most part in the $1980 \mathrm{~s}$, established a solid rationale for hospital-based influenza and pneumococcal vaccination. The implications of these findings for hospitals were discussed in review articles ${ }^{9-11}$ and in a chapter in a major textbook for infection control. ${ }^{12}$ As early as 1982 , the policy implications of hospital-based pneumococcal vaccination were presented in a symposium published in the Journal. ${ }^{13}$

Specific recommendations for hospital-based immunization were first published by the Centers for Disease Control and Prevention (CDC)'s Advisory Committee on Immunization Practices in the 1980s: for influenza vaccine in $1986^{14}$ and for pneumococcal vaccine in $1989 .{ }^{15}$ These recommendations were included in the Standards of Adult Immunization Practice that were issued by the National Coalition for Adult Immunization in $1990,{ }^{16}$ and they appeared in the second edition of the American College of Physicians' Guide for Adult Immunization (1990). ${ }^{17}$ Soon thereafter, hospital-based influenza and pneumococcal vaccination was recommended in the National Vaccine Advisory Committee's report on adult immunization ${ }^{18}$ and in a critical report published by the General Accounting Office. ${ }^{19}$ Subsequently, this strategy was included in the action 


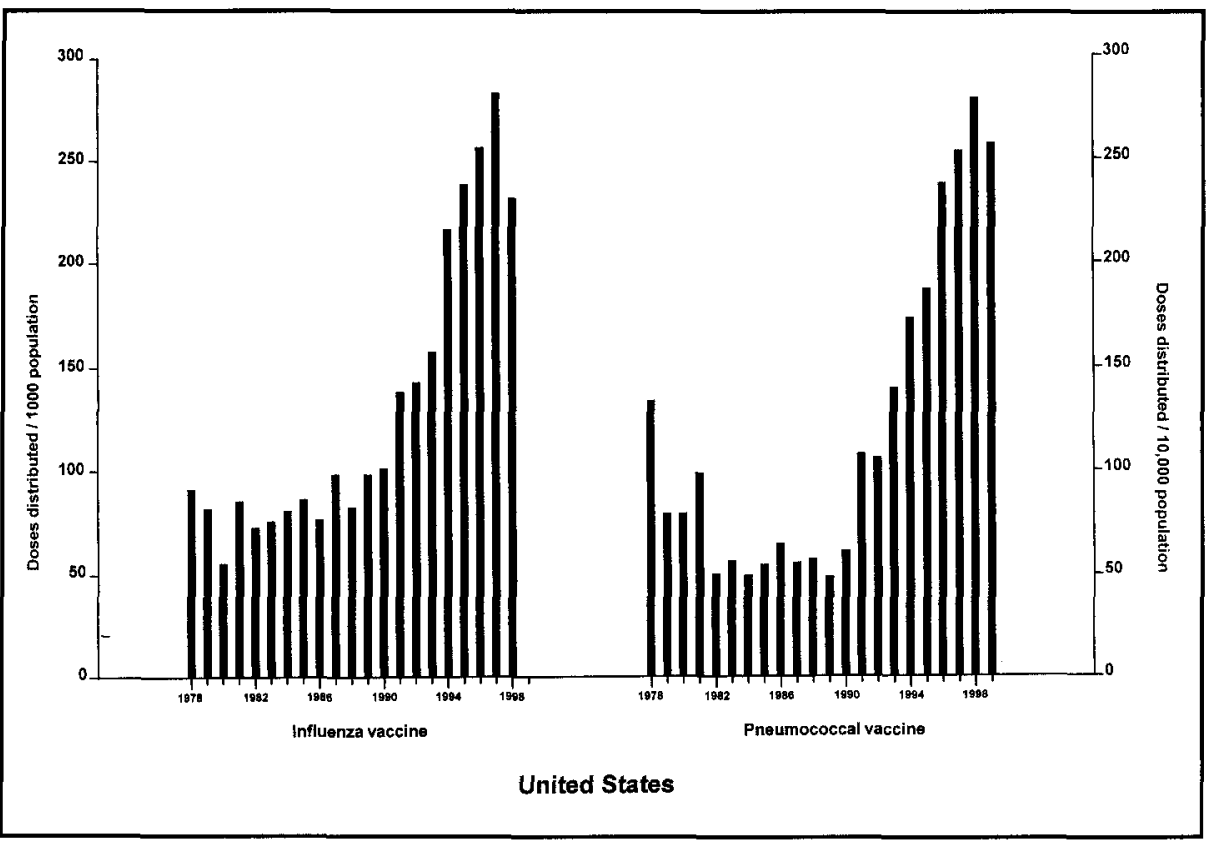

FIGURE. Influenza and pneumococcal vaccination in the United States, 1978-1999. The figure shows the numbers of doses of influenza and pneumococcal vaccines distributed each year per 1,000 and 10,000 population, respectively. Influenza vaccine data were not available for 1999 .

plan for adult immunization developed by the $\mathrm{CDC}$ and the Health Care Financing Administration (HCFA), ${ }^{20}$ and it was later endorsed by the Task Force on Community Preventive Services. ${ }^{21}$ It also was emphasized in a comprehensive report prepared for HCFA by the Rand Corporation to provide evidence-based recommendations for increasing the use of Medicare-funded preventivecare services. ${ }^{22}$

The community of infection control practitioners also has developed its own policy statements for hospitalbased influenza and pneumococcal vaccination, as noted in the guideline for prevention of nosocomial pneumonia issued by the CDC's Hospital Infection Control Practices Advisory Committee ${ }^{23}$ and in a statement by the American Hospital Association's Technical Panel on Infections Within Hospitals. ${ }^{24}$ Moreover, in issuing its 1992 position paper on immunizations, APIC stated, "APIC supports all efforts to reduce vaccine-preventable disease among adults by increasing the awareness of health care providers and the general public regarding the need for and the general benefits of immunizations." 25 It is worth noting the somewhat delayed appearance of these policy statements from the infection control community, and in particular the very general nature of APIC's 1992 statement, a statement that was republished in 1999 virtually unchanged. ${ }^{26}$

\section{CHANGES IN THE SCIENTIFIC UNDERSTANDING OF THE BENEFITS OF INFLUENZA AND PNEUMOCOCCAL VACCINATION}

The history of influenza and pneumococcal vaccination in the United States over the past 20 years can be conveniently summarized by depicting the annual distribution of the two vaccines as rates per 1,000 and 10,000 persons, respectively (Figure ${ }^{27-29}$; D.S.F., unpublished data). The use of influenza vaccine remained at relatively low levels during the 1980 s. Similarly, after an initial burst in the late 1970 s, the use of pneumococcal vaccine declined to disappointing levels in the 1980s.

Several reasons account for these low levels of vaccine use, including uncertainties about their clinical effectiveness and safety in older persons. Cost-effectiveness studies had been conducted for both vaccines by the US Congress Office of Technology Assessment (OTA) in the late $1970 \mathrm{~s}$, and the favorable results were published in the early $1980 \mathrm{~s}^{30,31}$ However, there was considerable reluctance to accept the OTA results for pneumococcal vaccination, because the analysis assumed vaccination was effective in preventing pneumococcal pneumonia in older people (both nonbacteremic and bacteremic cases) and clinical evidence for this in elderly people was unavailable. In addition, there was no effective public reimbursement for either vaccine. The Medicare statute did not authorize reimbursement for influenza vaccine, and, although Congress had authorized HCFA to provide Medicare reimbursement for the cost of pneumococcal vaccine in 1980 , the actual payment to physicians covered only the cost of the vaccine itself, not its administration. The amount of money physicians received for pneumococcal vaccination was little more than one half of the amount previously determined by OTA to be costeffective. In effect, the level of Medicare reimbursement constituted a financial disincentive to vaccinate patients. ${ }^{11}$

As shown in the Figure, there was a noticeable increase in the use of both vaccines in the early 1990s. For influenza vaccination, new information on its clinical effectiveness derived from population-based casecontrol ${ }^{32,33}$ and retrospective cohort studies ${ }^{34,35}$ was of 
great importance. For pneumococcal vaccination, the results of several earlier prospective clinical trials in older adults had been inconclusive, but findings from retrospective studies showing that vaccination was effective in preventing hospitalization for bacteremic or invasive pneumococcal disease ${ }^{36}$ and pneumonia (all causes) ${ }^{37}$ came to be more widely accepted. New information on low rates of vaccine-related adverse events was also helpful. ${ }^{38,39}$ In addition, there were new demonstrations of the indisputable economic benefits of influenza ${ }^{34}$ and pneumococcal ${ }^{37,40}$ vaccination: among elderly persons, both vaccinations were shown to be cost-saving. The Medicare Influenza Vaccine Demonstration, 1988 to 1992, drew special attention to influenza vaccination. ${ }^{11,41}$ As a result, many groups of investigators began to undertake studies to evaluate more effective ways of increasing the delivery of both vaccines. ${ }^{42}$

All of these scientific developments contributed to the increase in the use of influenza and pneumococcal vaccines in the $1990 \mathrm{~s}$. The most important development, however, probably was the congressional action that allowed HCFA to begin reimbursement in 1993 for the cost of influenza vaccine and the cost of administration for both influenza and pneumococcal vaccines. ${ }^{43}$ Despite these positive developments, in 1997 only $65 \%$ of elderly Americans received influenza vaccine, and only $45 \%$ had ever been given pneumococcal vaccine. ${ }^{44}$

\section{EXPERIENCE IN IMPLEMENTING HOSPITAL-BASED PROGRAMS FOR INFLUENZA AND PNEUMOCOCCAL VACCINATION}

Insofar as influenza and pneumococcal infections have been of concern to infection control practitioners, it has been primarily because they can cause nosocomial pneumonia. ${ }^{45-49}$ The concerns of these practitioners regarding influenza and pneumococcal vaccine have focused largely on improving influenza-vaccination uptake among healthcare workers in hospitals and among staff and residents of nursing homes and other long-term-care institutions. Interestingly, no article describing programs for vaccinating discharged patients with influenza or pneumococcal vaccines has ever been published in the pages of this Journal or in those of the other two major journals for infection control: American Journal of Infection Control and Journal of Hospital Infection (D.S.F., unpublished data).

Notwithstanding the apparent disinterest of the infection control community, several groups of investigators, usually led by academic general internists, family practitioners, geriatricians, or pharmacists, have undertaken programs for administering influenza and pneumococcal vaccines to patients at the time of hospital discharge. The published studies for pneumococcal vaccination are summarized in Table $2 .^{50-56}$ All of the studies differed in their methodologies, as well as in the interventions tested, and few would meet current evidence-based standards for evaluating health care. Nonetheless, the results indicate that any intervention almost always was better than no
TABLE 2

EFFECtIVENESS of PNeumococcal Vaccination Programs for Patients Discharged From Hospitals

\begin{tabular}{|c|c|c|c|}
\hline \multirow[b]{2}{*}{ Study, y } & \multirow[b]{2}{*}{ Intervention } & \multicolumn{2}{|c|}{ Vaceination Rate (\%) } \\
\hline & & $\begin{array}{l}\text { Control } \\
\text { Group }\end{array}$ & $\begin{array}{c}\text { Intervention } \\
\text { Group }\end{array}$ \\
\hline $\begin{array}{l}\text { Overhage, }^{50} \\
1996\end{array}$ & $\begin{array}{l}\text { Computer reminder- } \\
\text { house staff }\end{array}$ & 2 & 2 \\
\hline $\begin{array}{r}\text { Klein, }^{51} \\
1983\end{array}$ & Chart reminder & 2 & 10 \\
\hline $\begin{array}{r}\text { Klein, }^{51} \\
1983\end{array}$ & $\begin{array}{l}\text { Chart reminder+ } \\
\text { poster }\end{array}$ & 2 & 20 \\
\hline $\begin{array}{l}\text { Vondracek, } \\
1998\end{array}$ & Chart reminder & 0 & 24 \\
\hline $\begin{array}{c}\text { Landis, }{ }^{\star 53} \\
1996\end{array}$ & $\begin{array}{l}\text { Standing order- } \\
\text { nurse }\end{array}$ & 4 & 32 \\
\hline $\begin{array}{c}\text { Clancy, }{ }^{54} \\
1992\end{array}$ & $\begin{array}{l}\text { Computer reminder- } \\
\text { nurse }\end{array}$ & 4 & 50 \\
\hline $\begin{array}{c}\text { Bloom, } \\
1988\end{array}$ & $\begin{array}{l}\text { Pamphlet }+ \text { nurse }+ \\
\text { volunteer }\end{array}$ & 0 & 75 \\
\hline $\begin{array}{r}\text { Klein, }{ }^{56} \\
1986\end{array}$ & Standing order-nurse & 0 & 78 \\
\hline
\end{tabular}

* Includes only patients whose need for vaccinations was assessed. All patients in the intervention group were assessed, but only $46 \%$ of control patients were assessed.

intervention at all. Furthermore, assigning responsibility for carrying out the intervention to a specific individual, usually a nurse, was undeniably more effective than less direct interventions such as chart reminders. Interestingly, a computer reminder for nurses ${ }^{54}$ achieved noteworthy results with relatively little effort: an additional section related to pneumococcal vaccination was added to the hospital's computerized discharge protocol that all nurses followed when they discharged their patients. No in-service education or other special efforts were needed to achieve these results.

The most remarkable example of success with hospital-based immunization is the program that has been conducted at the Minneapolis Veterans Affairs Medical Center (VAMC) since 1984. This hospitalwide program initially focused on influenza vaccination of outpatients and used a combination of administrative-, organizational-, and patient-oriented interventions. ${ }^{57,58}$ No specific attempts were made to involve physicians. Instead, the program was implemented by nurses according to a hospital policy that allowed them to vaccinate patients without a signed physician's order. By 1987, the program was vaccinating $60 \%$ of the hospital's elderly outpatients ${ }^{57}$; by the late $1990 \mathrm{~s}$, almost $90 \%$ were regularly receiving influenza vaccine, most of them through the hospital's program..$^{59}$

Beginning with the influenza vaccination season in 1989 , the Minneapolis VAMC outpatient vaccination program was expanded to include hospitalized inpatients. ${ }^{60} \mathrm{~A}$ standing order allowed nurses to vaccinate any inpatient on the day of discharge, as long as it was not contraindicated. 
TABLE 3

Influenza and Pneumococcal Vaccination of Patients $\geqslant 65$ Years in Age Discharged From Hospitals, 1998 to $1999 *$

\begin{tabular}{|c|c|c|c|c|c|}
\hline Vacclne & $\begin{array}{l}\text { Discharge } \\
\text { Dlagnosis }\end{array}$ & $\begin{array}{c}\text { No. of } \\
\text { Ellgible Patients }\end{array}$ & No. Screened (\%) & $\begin{array}{l}\text { No. Screened } \\
\text { and Found } \\
\text { Already to Be } \\
\text { Vaccinated (\%) }\end{array}$ & $\begin{array}{l}\text { No. Sereened, Not } \\
\text { Already Vacclnated, } \\
\text { and Vaccinated } \\
\text { Before Dlscharge (\%) }\end{array}$ \\
\hline \multirow[t]{2}{*}{ Influenza ${ }^{\ddagger}$} & Pneumonia & 14,114 & $2,462 \quad(17.4)$ & $946 \quad(38.4)$ & $350 \quad(23.1)$ \\
\hline & Other conditions & 27,312 & $3,037 \quad(11.1)$ & $1,119 \quad(36.8)$ & $341 \quad(17.8)$ \\
\hline \multirow[t]{2}{*}{ Pneumococcal ${ }^{\S}$} & Pneumonia & 26,186 & $3,312 \quad(12.6)$ & $1,792 \quad(54.1)$ & $359 \quad(23.6)$ \\
\hline & Other conditions & 83,381 & $6,045 \quad(7.2)$ & $3,361 \quad(55.6)$ & $229 \quad(8.5)$ \\
\hline
\end{tabular}

* Preliminary findings from the Medicare National Pneumonia Project. The findings are based on a comprehensive review of the medical records of patients discharged (first-listed diagnosis) after hospitalization with pneumonia and three other conditions (congestive heart failure, acute myocardial infarction, and cerebrovascular accident). In each of the 50 states, the District of Columbia, and Puerto Rico, approximately 750 medical records for each of the four conditions were reviewed. (D.B., P.H., unpublished data).

$\dagger$ Excludes patients aged $\leqslant 65 \mathrm{y}$ and those who died in hospital who were transferred to another acute-care facility or left the hospital against medical advice.

† Includes patients discharged from October 1-December 31, 1998. Excludes patients discharged with influenza (ICD-9-CM 487.0) during this period.

$\S$ Includes all patients discharged during a 6-month period from July 1, 1998-March 31, 1999. The 3-month period October 1, 1998-December 31, 1998, was included in each 6-month period.

Influenza vaccine was administered either on the hospital ward itself or, to reduce the work load on ward nursing staff, in the hospital's walk-in "flu-shot" clinic. Again, physicians were not involved in the daily operation of the program. A follow-up survey of all medical inpatients discharged during the 1989 vaccination season showed that $79 \%$ had been vaccinated, $92 \%$ of them at the time of hospital discharge. The inpatient program was continued on an annual basis, and by the mid- 1990 s vaccination rates of $82 \%$ to $86 \%$ were achieved. ${ }^{59}$ The program was also exported to two smaller community hospitals in 1991, and $40 \%$ of discharged patients were vaccinated. ${ }^{61}$

In 1994, the Minneapolis VAMC added pneumococcal vaccination to its outpatient flu-shot program; vaccination rates among elderly patients rose from $39 \%$ to $66 \% 2$ years later. Pneumococcal vaccination was added to the inpatient program in 1995; $67 \%$ of discharged patients were vaccinated in each of the following 2 years. ${ }^{59}$ It is important to note that prior to 1994 there had been no spillover effect of the influenza vaccination program on the hospital's use of pneumococcal vaccine; very few doses were used until the vaccine was explicitly incorporated into the hospital's vaccination programs. Equally important, once pneumococcal vaccination was added to both the outpatient and inpatient programs, there was no deleterious effect on rates of influenza vaccination.

Until recently there has been no information on the extent to which hospitals in the United States routinely assess the immunization status of hospitalized patients or administer influenza and pneumococcal vaccines before discharge to patients who need them. However, in the early 1990 s, a survey of elderly patients hospitalized for pneumonia documented many previously missed opportunities for vaccination. ${ }^{62}$ Fortunately, information on these questions is being gathered by HCFA's National Pneumonia Project. The project's goal is to reduce the morbidity and mortality among Medicare's 39 million beneficiaries. Influenza and pneumococcal vaccination of hospital inpatients is a priority. Preliminary findings from this project are shown in Table 3. Disappointingly, they show that the medical records of few patients contained evidence that their physicians and nurses had inquired about their vaccination status. However, among the few patients that were screened for influenza vaccination, approximately one third were found to have been vaccinated already, and another $20 \%$ were vaccinated before discharge. Fewer patients were screened for pneumococcal vaccination, but among those that were, slightly more than one half had been vaccinated already. Of those who had not been vaccinated, pneumonia patients were more likely to be vaccinated before discharge than were those with other conditions. The opportunity to immunize among the unscreened majority of patients was probably just as great, but none of them received vaccines prior to discharge.

Currently, more detailed evaluations of hospitalbased inpatient influenza or pneumococcal vaccination programs are being undertaken by most Medicare Peer Review Organizations. ${ }^{22}$ These evaluations should provide important new information on the characteristics and achievements of these programs.

\section{PRACTICAL ISSUES FOR HOSPITAL-BASED VACCINATION}

Among successful programs for hospital-based influenza and pneumococcal vaccinations, a standing order is probably the most important feature. The Advisory Committee on Immunization Practices has specifically recommended that standing orders be used to increase adult vaccination rates in all settings. ${ }^{63}$ Furthermore, none of the successful programs described thus far in the literature has depended on active physician participation. Instead, nurses or pharmacists ${ }^{52,64}$ have been responsible for their implementation.

Several concerns have been raised, however, about vaccinating discharged patients. One is the issue of the immunogenicity of the two vaccines when they are given to persons who are recovering from illnesses serious enough to have caused hospitalization. Influenza vaccine is as immunogenic and acceptable when given to patients at the 
time of hospital discharge as it is when they are vaccinated 4 to 8 weeks later. ${ }^{65}$ Unfortunately, similar information has yet to be obtained for pneumococcal vaccine, although the vaccine is immunogenic when it is given to patients 1 to 2 months after hospital discharge for pneumonia. ${ }^{66}$

There also has been concern about inadvertent revaccination of discharged patients who previously received pneumococcal vaccine but cannot provide a reliable vaccination history. Self-reports of recent pneumococcal vaccination by elderly persons are accurate in most instances, however. ${ }^{67}$ Also, inadvertent revaccination 3 or more years following initial vaccination is safe and is not associated with greater rates of serious local or systemic adverse reactions. ${ }^{39}$ There has also been concern that vaccinating discharged patients could threaten the continuity of care and damage relationships between office-based physicians and their patients. This concern should not take precedence over the well-documented evidence that large numbers of older persons who are hospitalized have not been appropriately vaccinated. Encouragingly, one study has reported that, among 26 community-based physicians affiliated with a large hospital, all felt it was appropriate for hospitals to provide immunizations, and only 1 felt that a nurse needed to obtain a physician's approval before vaccinating discharged patients. ${ }^{53}$

One problem sometimes encountered is the frequent refusal of discharged patients to be vaccinated. ${ }^{53}$ Active involvement of physicians in offering vaccines can be very effective, but experience has shown they rarely offer vaccines to their discharged patients. Nurses and other healthcare staff who are enthusiastic and assertive in implementing standing orders for vaccination are usually an effective alternative. The long-term durability of hospital-based vaccination programs is essentially unknown; only one institution has reported sustained success in vaccinating its discharged patients. ${ }^{59}$

One major concern is the issue of how hospitals will pay for the costs of vaccinating discharged patients. If vaccination were considered to be one of the many services covered by Medicare's diagnosis-related-group (DRG)-based payment for hospital care, the additional cost would make hospitals reluctant to undertake vaccination programs. However, because Medicare recognizes the importance of influenza and pneumococcal vaccination for older people, it provides additional reimbursement for vaccination over and above the basic DRG payment for inpatient care. Hospitals are allowed to submit "roster bills" to reduce the administrative burden of submitting individual claims for vaccinations. Medicare officials have undertaken special efforts to ensure that hospitals understand this.

A final issue, most often unstated, is the perception that pneumonia is "the old man's friend" and that, for older patients who already have serious underlying conditions requiring hospital care, influenza and pneumococcal vaccines can be withheld. Contrary to this belief, however, is the observation that the long-term outcomes of patients who have been discharged following hospitalization for pneumonia are little different from those of elderly persons who have not been hospitalized with pneumonia. ${ }^{68}$ This finding strongly suggests that vaccination, not pneumonia, should be regarded as the old man's friend.

\section{AN ENHANCED ROLE FOR INFECTION CONTROL PRACTITIONERS IN PROGRAMS FOR HOSPITAL-BASED INFLUENZA AND PNEUMOCOCCAL VACCINATION}

Experience over the past 2 decades has shown convincingly that there is a solid epidemiological rationale for vaccinating hospital-discharged patients with influenza and pneumococcal vaccines. These two vaccines are safe, welltolerated, clinically effective, and cost saving when given to elderly persons. Organized programs for vaccine delivery have succeeded in vaccinating high proportions of discharged patients who otherwise would have remained unvaccinated. Despite all the evidence indicating that such programs could prevent large numbers of unnecessary hospitalizations and deaths, administering influenza and pneumococcal vaccines to patients when they are being discharged is seldom done in the great majority of American hospitals. If the overall activities of infection control practitioners are cost-effective, ${ }^{69}$ and if these efforts are increasingly of the nature of "interventional epidemiology,"70 it is hard to imagine any intervention other than vaccinating discharged patients that has a better epidemiological rationale or that could be more cost-effective.

The introduction to the 1982 symposium on strategies for implementing pneumococcal vaccination concluded by saying,

"The readers of Infection Control constitute a community of physicians, scientists and health care workers primarily concerned with infections in the hospital setting. However, an important part of controlling infections in hospitals is preventing their ever occurring in the community. The prevention of disease and the promotion of health can and should be of as much concern to those who work in hospitals as it is to those who work in other sectors of our health care system. If this symposium increases awareness of this compelling task, it will have served its purpose." 13

Medicare's National Pneumonia Project reflects the seriousness of Medicare's commitment to ensure that older Americans receive the benefits of influenza and pneumococcal vaccination. Medicare currently spends $\$ 100$ to $\$ 110$ million each year reimbursing physicians and institutions for influenza and pneumococcal vaccination (P.H., D.B., unpublished data). It is not known what proportion of these funds are used to reimburse hospitals for vaccinating their inpatients; yet, access to these vaccines will never be better than at the time of hospital discharge. Like Willie Sutton, Medicare understands clearly that vaccinating discharged patients is "where the money is."

Organizing effective programs for hospital-based influenza and pneumococcal vaccination is undeniably a compelling task. It demands and deserves the best efforts and the imagination of everyone in the infection control community. 


\section{REFERENCES}

1. Fedson DS, Kessler HA A hospital-based influenza immunization program, 1977-78. Am J Public Health 1983;73:442-445.

2. Schoenbaum S. Influenza vaccine: delivering the goods. Am J Public Health 1983;73:365-366.

3. Fedson DS, Wajda A, Nicol JP, Roos LL. Disparity between influenza vaccination rates and risks for influenza-associated hospital discharge and death in Manitoba in 1982-1983. Ann Intern Med 1992;116:550-555.

4. Fedson DS, Baldwin JA. Previous hospital care as a risk factor for pneumonia. Implications for immunization with pneumococcal vaccine. JAMA 1982;248:1989-1995.

5. Fedson DS, Chiarello LA. Previous hospital care and pneumococcal bacteremia. Importance for pneumococcal immunization. Arch Intern Med 1983;143:885-889.

6. Fedson DS. Improving the use of pneumococcal vaccine through a strategy of hospital-based immunization: a review of its rationale and implications. I Am Geriatr Soc 1985;33:142-150.

7. Lipsky BA, Boyko EJ, Inui TS, Koepsell TD. Risk factors for acquiring pneumococcal infections. Arch Intern Med 1986;146:2179-2185.

8. Fedson DS, Harward MP, Reid RA, Kaiser DL. Hospital-based pneumococcal immunization. Epidemiologic rationale from the Shenandoah study. JAMA 1990;264:117-122.

9. Fedson DS. Influenza and pneumococcal immunization strategies for physicians. Chest 1987;91:436-443.

10. Williams WW, Hickson MA, Kane MA, Kendal AP, Spika JS, Hinman AR. Immunization policies and vaccine coverage among adults. The risk for missed opportunities. Ann Intern Med 1988;108:616-625.

11. Fedson DS. Clinical practice and public policy for influenza and pneumococcal vaccination of the elderly. Clin Geriatr Med 1992;8:183-199.

12. Fedson DS. Immunizations for healthcare workers and patients in hospitals. In: Wenzel RP, ed. Prevention and Control of Nosocomial Infections. Baltimore, MD: Williams \& Wilkins; 1987:116-174

13. Fedson DS, Rytel MW, Willems JS, Riddiough MA, Dull HB, Tarlov AR Pneumococcal immunization: strategies for implementation. Infect Control 1982;4:293-298.

14. Centers for Disease Control. Prevention and control of influenza. Recommendations of the Immunization Practices Advisory Committee (ACIP). MMWR 1986;35:317-326,331.

15. Centers for Disease Control. Pneumococcal polysaccharide vaccine. Recommendations of the Immunization Practices Advisory Committee (ACIP), MMWR 1989;38:38-46.

16. Centers for Disease Control. Public health burden of vaccinepreventable disease among adults: standards of adult immunization practice. MMWR 1990;39:725-729.

17. American College of Physicians Task Force on Adult Immunization. Guide for Adult Immunization. 2nd ed. Philadelphia, PA: American College of Physicians; 1990.

18. Fedson DS. Adult immunization: a summary report for the National Vaccine Advisory Committee. JAMA 1994;272:1133-1137.

19. General Accounting Office. Immunization. HHS Could Do More to Increase Vaccination Among Older Adults. GAO-PEMD-95-14. Washington, DC: United States General Accounting Office; 1995:1-66.

20. Centers for Disease Control and Prevention. Adult Immunization Action Plan: Report of the Workgroup on Adult Immunization. Atlanta, GA: US Department of Health and Human Services, CDC; 1998. http://www.cdc.gov/od/nvpo/adult.htm.

21. Task Force on Community Preventive Services. Recommendations regarding interventions to improve vaccination coverage in children, adolescents, and adults. Am J Prev Med 2000;18(suppl):92-140.

22. Health Care Financing Administration. Evidence Report and EvidenceBased Recommendations: Interventions That Increase the Utilization of Medicare-Funded Preventive Services for Persons Age 65 and Older. HCFA publication no. HCFA-02151. Baltimore, MD: US Department of Health and Human Services, Health Care Financing Administration; 1999.

23. Hospital Infection Control Practices Advisory Committee, Centers for Disease Control and Prevention. Guideline for prevention of nosocomial pneumonia. Infect Control Hosp Epidemiol 1994;15:587-627.

24. American Hospital Association Technical Panel on Infections within Hospitals. Management advisory-health care delivery: immunization. Am J Infect Control 1994;22:42-46.

25. Association for Practitioners of Infection Control. Position paper: immunizations. Am J Infect Control 1992;20:131-132.

26. Association for Professionals in Infection Control and Epidemiology. Position paper: immunizations. Am I Infect Control 1999;27:52-53.

27. Fedson DS, Hannoun C, Leese J, Sprenger MJ, Hampson AW, BroJorgensen $\mathrm{K}$, et al. Influenza vaccination in 18 developed countries, 1980 1992. Vaccine 1995;13:365-369.

28. Ambrosch F, Fedson DS. Influenza vaccination in 29 developed countries: an update to 1997. Pharmacoeconomics 1999;16(suppl 1):47-54.

29. Fedson DS. Pneumococcal vaccination in the United States and 20 other developed countries, 1981-1996. Clin Infect Dis 1998;26:1117-1123.

30. Riddiough MA, Sisk JE, Bell JC. Influenza vaccination: cost-effectiveness and public policy. JAMA 1983;249:3189-3195.

31. Sisk JE, Riegelman RK. Cost effectiveness of vaccination against pneumococcal pneumonia: an update. Ann Intern Med 1986;104:79-86.

32. Foster DA, Talsma A, Furamoto-Dawson A, Ohmit SE, Margulies JR, Arden NH, et al. Influenza vaccine effectiveness in preventing hospital ization for pneumonia in the elderly. Am J Epidemiol 1992;136:296-307.

33. Fedson DS, Wajda A, Nicol JP, Hammond GW, Kaiser DL, Roos LL. Clinical effectiveness of influenza vaccination in Manitoba. JAMA 1993;270:1956-1961.

34. Nichol KL, Margolis KL, Wuorenma J, von Sternberg T. The efficacy and cost-effectiveness of vaccination against influenza among elderly persons living in the community. $N$ Engl J Med 1994;331:778-784.

35. Nichol KL, Wuorenma J, von Sternberg $T$. The benefits of influenza vaccination for low-, intermediate-, and high-risk senior citizens. Arch Intern Med 1998;158:1769-1776.

36. Fedson DS. Clinical effectiveness of pneumococcal vaccination: a brief review. Vaccine 1999;17(suppl):S85-\$90.

37. Nichol KL, Baken L, Wuorenma J, Nelson A. The health and economic benefits associated with pneumococcal vaccination of elderly persons with chronic lung disease. Arch Intern Med 1999;159:2437-2442.

38. Margolis KL, Nickol KL, Poland GA. Pluhar RE. Frequency of adverse reactions to influenza vaccine in the elderly. A randomized placebocontrolled trial. JAMA 1990;264:1139-1141.

39. Jackson LA, Benson P, Sneller VP, Butler JC, Thompson RS, Chen RT, et al. Safety of revaccination with pneumococcal polysaccharide vaccine. JAMA 1999;281:243-248.

40. Sisk JE, Moskowitz AJ, Whang W, Lin JD, Fedson DS, McBean AM, et al. Cost effectiveness of vaccination against pneumococcal bacteremia among elderly people. JAMA 1997;278:1333-1339.

41. Centers for Disease Control and Prevention. Medicare influenza vaccine demonstration-selected states, 1988-1992. MMWR 1992;41:152-155.

42. Gyorkos TW, Tannenbaum TN, Abramowicz M, Bedard L, Carsley J Franco ED, et al. Evaluation of the effectiveness of immunization delivery methods. Can J Public Health 1994:85(suppl 1):S14 S30.

43. Centers for Disease Control and Prevention. Final results: Medicare influenza vaccine demonstration-selected states, 1988-1992. MMWR 1993;42:601-604.

44. Centers for Disease Control and Prevention. Influenza and pneumococcal vaccination levels among adults aged $>65$ years-United States. MMWR 1998;47:797-802.

45. Pachuki CT, Walsh Pappas SA, Fuller GF, Krause SL, Lentino JR, Schaff DM. Influenza A among hospital personnel and patients. Implications for recognition, prevention, and control. Arch Intern Med 1989;149:77-80.

46. Glezen WP, Falcao O, Cate TR, Mintz AA. Nosocomial influenza in a general hospital for indigent patients. Can J Infect Control 1991;6:65-67.

47. Adal KA, Flowers RA, Anglim AM, Hayden FG, Titus MG, Coyner BJ, et al. Prevention of nosocomial influenza. Infect Control Hosp Epidemiol 1996;17:641-648.

48. Chadwick PR, Panagea S, Panigrahi H, Worsley MA, McCann D. Outbreak of infection with penicillin-resistant pneumococci. J Hosp Infect 1996;33:304-306.

49. de Galan BE, van Tilburg PM, Sluijter M, Mol SJ, de Groot R, Hermans PW, et al. Hospital-related outbreak of infection with multidrug-resistant Streptococcus pneumoniae in The Netherlands. J Hosp Infect 1999;42:185192.

50. Overhage JM, Tierney WM, McDonald CJ. Computer reminders to implement preventive care guidelines for hospitalized patients. Arch Intern Med 1996;156:1551-1556.

51. Klein RS, Adachi N. Pneumococcal vaccine in the hospital. Improved use and implications for high-risk patients. Arch Intern Med 1983;143:1878 1881.

52. Vondracek TG, Pham TP, Huycke MM. A hospital-based pharmacy intervention program for pneumococcal vaccination. Arch Intern Med 1998;158:1543-1547.

53. Landis S, Scarbrough ML. Using a vaccine manager to enhance inhospital vaccine administration. I Fam Pract 1995;41:364-369.

54. Clancy CM, Gelfman D, Poses RM. A strategy to improve utilization of pneumococcal vaccine. J Gen Intern Med 1992;7:14-18.

55. Bloom HG, Bloom JS, Krasnoff L, Frank AD. Increased utilization of influenza and pneumococcal vaccines in an elderly hospitalized population. J Am Geriatr Soc 1988;36:897-901.

56. Klein RS, Adachi N. An effective hospital-based pneumococcal immunization program. Arch Intern Med 1986;146:327-329.

57. Nichol KL, Korn JE, Margolis KL, Poland GA, Petzel RA, Lofgren RP, et al. Achieving the national health objective for influenza immunization Success of an institution-wide vaccination program. $\mathrm{Am} J \mathrm{Med}$ 1990;89:156-160.

58. Nichol KL. Long-term success with the national health objective for influenza vaccination: an institution-wide model. I Gen Intern Med 
1992;7:595-600.

59. Nichol KL. Ten-year durability and success of an organized program to increase influenza and pneumococcal vaccination rates among high-risk adults. Am J Med 1998;105:385-392.

60. Nichol KL. Improving influenza vaccination rates for high-risk inpatients: a successful for hospital-wide program. Am J Med 1991;91: 584-588.

61. Crouse BJ, Nichol K, Peterson DC, Grimm MB. Hospital-based strategies for improving influenza vaccination rates. I Fam Pract 1994;34: 258-261.

62. Centers for Disease Control and Prevention. Missed opportunities for pneumococcal and influenza vaccination of Medicare pneumonia inpatients-12 western states, 1995. MMWR 1997;46:919-923.

63. Centers for Disease Control and Prevention. Use of standing orders programs to increase adult vaccination rates. Recommendations of the Advisory Committee on Immunization Practices. MMWR 2000;49 (RR-1):21-26.
64. Grabenstein JD. Pharmacists as vaccine advocates: roles in community pharmacies, nursing homes and hospitals. Vaccine 1998;16:705-710.

65. Aoki FY, Sekla LH, Pitch S, et al. Immunogenicity and acceptability of influenza vaccine (V) administered at hospital discharge. Clin Invest Med 1990;13:B58. Abstract.

66. Hedlund JU, Kalin ME, Ortqvist AB, Henrichsen J. Antibody response to pneumococcal vaccine in middle-aged and elderly patients recently treated for pneumonia. Arch Intern Med 1994;154:1961-1965.

67. Mac Donald R, Baken L, Nelson A, Nichol KL. Validation of self-report of influenza and pneumococcal vaccination status in elderly outpatients. Am J Prev Med 1999;16:173-177.

68. Fedson DS, Wadja A, Nicol JP, Roos LL. "The old man's friend." Lancet 1993;342:561.

69. Wenzel RP. The economics of hospital infection. J Hosp Infect 1995;31:7987.

70. Garcia R, Barnard B, Kennedy V. The fifth evolutionary era in infection control: interventional epidemiology. Am J Infect Control 2000;28:30-43. 